This is your page to write to and open up topics for debate, reply to each other and offer advice. The letters we have for this issue cover the importance of an integrated team and give hope for dental nurse training. What are your thoughts and contributions? These can be about your profession only or about working in dentistry in general.

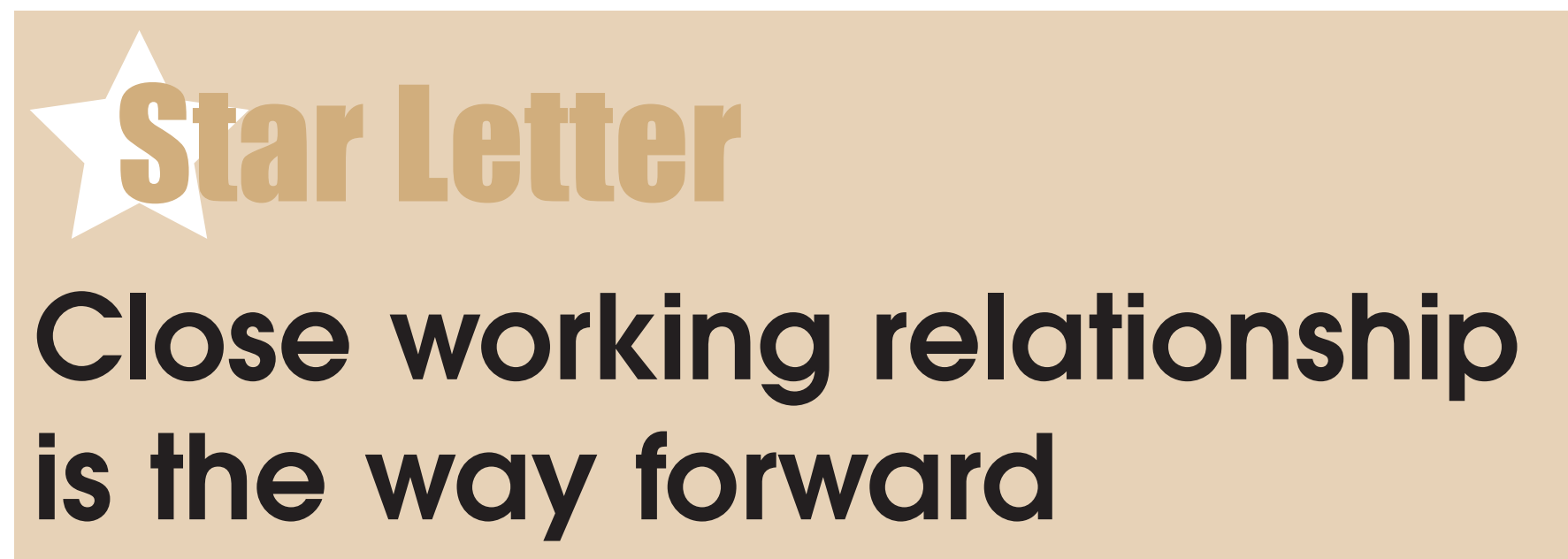

Dental manpower is indisputably in short supply and promises by government of increases are welcome. But one hears predominantly of more dentists being promised - another 1000 dentists in the short-term from a variety of sources and, when they graduate in five years time, another 170 trained in the UK.

But do we need all that many more dentists? There are so many activities which can be delegated to ancillary personnel who are properly trained. We know that dental disease is decreasing and statistics indicate that the decay experience of children is likely to stay static over the next 20 years.

It is also known that the majority of caries in children is confined to a relatively small section of the population and that large numbers of children experience no caries throughout their childhood.

Is it really necessary for a five year qualified highly paid dentist to 'check' every child's dental health every six months? Could this be delegated to therapists? I am not disputing that children should be seen every six months since, children in particular, if caries is present, need to be treated promptly. Their dental development also needs regular assessment.

But I am sure that a closely led team of a dentist and therapist(s) could develop an understanding wherein the therapist consults a dentist in order to provide a prescription/second opinion when a problem is detected. In treating adults, a similar approach could be adopted.

The key is in the 'closely led team' headed by a dentist with mutual respect being developed between the parties for each other's roles. Hygienists form another branch of this team: their value is well documented and widely appreciated.

Again, the key is a close working relationship between dentist, hygienist and patient.

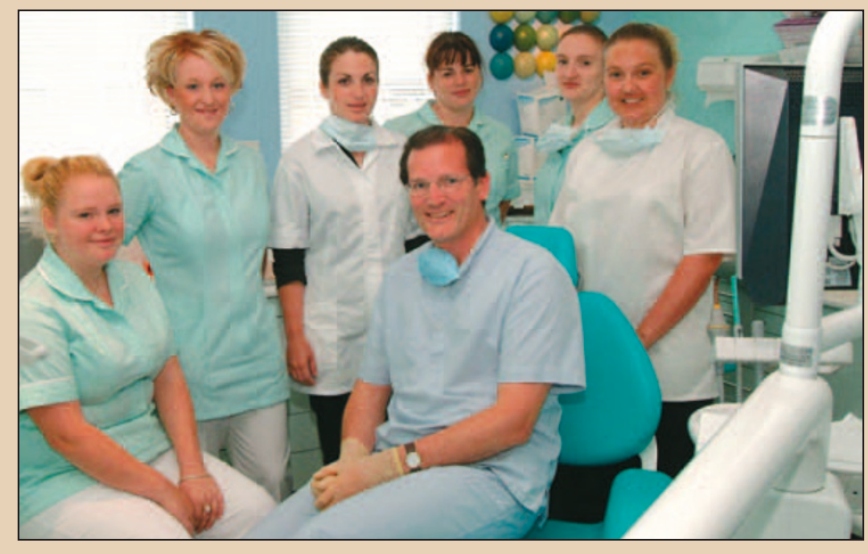

The team at Queensferry Dental Surgery, Flintshire, a BDA Focus Award winner

Why then do we not hear of promises by government of more training places for such valuable personnel?

As treatment planning becomes more complex and patients become more demanding, there will be plenty of work for the current generations of dentists at least until the dentally fit youth of today reach middle age! And they will all need treatment for erosion!

By way of increasing PCDs, I was pleased to see the advanced stage of development of some universities in increasing places for PCDs.

It would be nice to hear more openly of these developments so that all parties delivering dental care might be more accurately informed as to future manpower developments and begin to develop the mutual respect referred to above.

Auriel Gibson, GDP, Norfolk 


\section{Dental nurse training no longer in crisis}

As a post script to my letter in the Autumn issue of Vital, as a result of good co-ordination between the profession, NHS management and colleges, our dental advisers have pursuaded local diploma courses to get back off the ground again.

I believe we now have around 75 places now available masterminded by the Norfolk dental advisers. Clearly there is still a long way to go before we get the NVQ system up and running.

\section{Linda Hillman}

Immediate past Chair,

Norfolk and Norwich Section BDA

\section{Vital responds:}

Vital thanks Linda for her promising update on their situation in Norfolk and are pleased to publish the following letter from Andy, a Dental Adviser for Norfolk.

After our recent meetings we have now reestablished approximately 60 diploma course places and a reasonably local college (Lowesoft college - Suffolk) has come into Norwich to provide an NVQ course for about 15 people. The area's past experience with NVQ providers has not been good but we have high hopes that it will work this time.

As far as additional NVQ courses are concerned I am led to believe that these take a lot

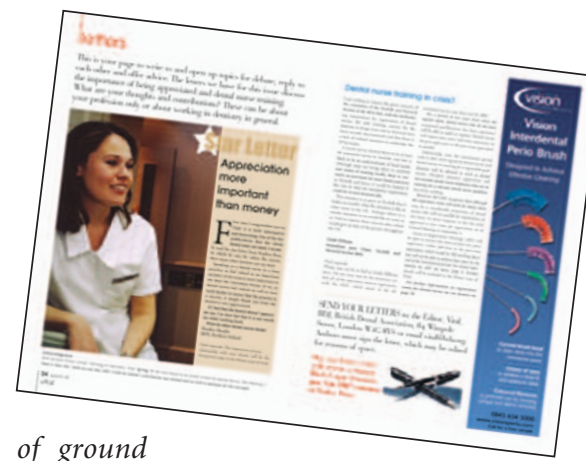

of ground

work before approval is given. This is

more achievable by the educational colleges since they know the system and already have the structures in place for other NVQ courses. I am led to believe that it will probably take about a year or so to get the course available if the local educational courses wish to push it along. At present they seem reluctant to do this but further meetings are planned.

I think one of the difficulties for the Dental Nursing NVQ is getting the assessors for the course and I believe the current remuneration structure for the assessors doesn't help this.

I feel the profession needs to debate the whole issue around NVQ provision / funding particulary when the courses are not in areas of major population density.

Andy Furniss

Dental Adviser, Norfolk

SEND YOUR LETTERS to: the Editor,

Vital Magazine, BDJ, Nature Publishing Group, 4-6 Crinan Street, London NI 9XW or email vitaleditorial@nature.com. Authors must sign the letter, which may be edited for reasons of space.

Our star letter writer will receive a Sonnet Black Laque fountain pen (£90 RRP) courtesy of Parker Pens.

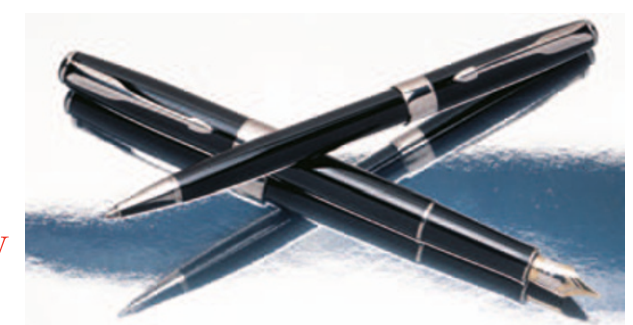

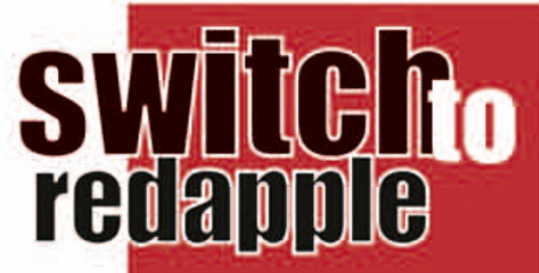

We

stock:

Alkapharm UK

b. Blen fir

Centrix

coltène $x$,

whaledent

DARAY

Dentaf?

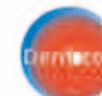

DENSPLY

DÜRR

3M ESPE

'CAC',

Keraeus

ivoclar

vivadeni

$\mathrm{KaVo}$

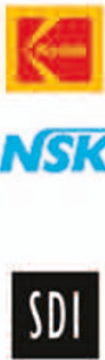

- Over 13,000 products

- All well-known manufacturers

- Special offers

- No minimum order

sdskerr

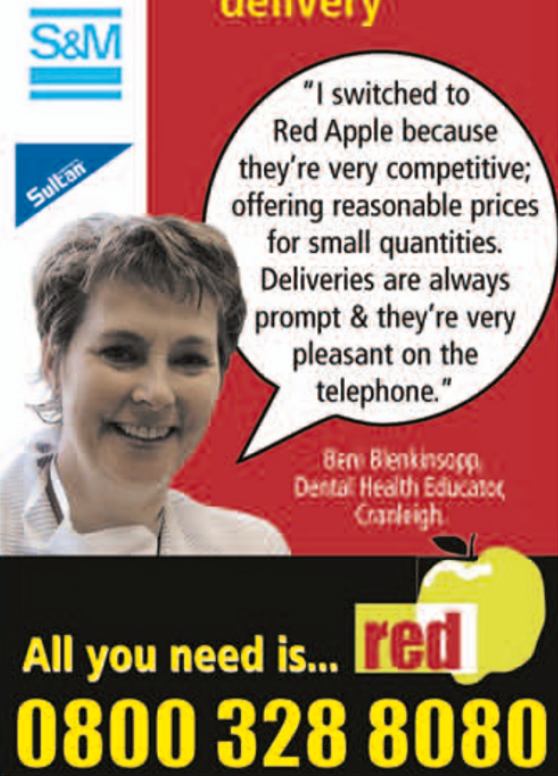

- Fast, FREE delivery 